\title{
Attitudes of general psychiatrists to child sexual abuse
}

\author{
Bisa HaEger, Registrar in Psychiatry, Royal Free Hospital, London NE3 and JoY \\ Dalton, Consultant in Psychiatry, Whittington and Friern Hospital, London N19
}

The incidence of child sexual abuse varies according to definitions and methods used. The MORI Poll $1984^{1}$ found it to be $12 \%$ for girls and $8 \%$ for boys and to occur across all the social classes using this definition: "A child (anyone under 16 years) is sexually abused when another person, who is sexually mature, involves the child in any activity which the other person expects to lead to their own sexual arousal. This might involve intercourse, touching, exposure of the sexual organs, showing pornographic material or talking about sexual things in an erotic way". The majority of studies have shown that these experiences can have adverse psychological effects, but the effect on the clinical practice of general psychiatrists seems to be too small if one considers the estimated 4.5 million adults in Great Britain who have been sexually abused as children. We thought that this could be related to attitudes rather than knowledge of the subject.

\section{The study}

To test this hypothesis a questionnaire with a covering note was designed and administered to general psychiatrists in a London teaching hospital. Out of the 49 psychiatrists, 35 replied ( 23 men and 13 women) thus giving a $71 \%$ response rate (one questionnaire was only partially filled and therefore not used in the analysis, three were returned unfilled, and the rest did not respond). The questionnaire was in the forced choice answer form and contained the following categories: information (signs and psychological consequences), blaming the victim, denial of sexual abuse by the profession, offender treatment, issues of power, moral and political stance (e.g. recognition of the status of women and children in society). The definition of child sexual abuse as above was used.

\section{Denial}

There was $100 \%$ agreement that there was an increased number of child sexual abuse cases being reported; $40 \%$ thought they did not know the incidence of the problem, some stating that this was due to the variable epidemiological data. However, the range given for boys was from $0.2 \%$ to $60 \%$ and for girls $0.5 \%$ to $60 \%$.
The results show that $89 \%$ of the sample believe that when a child brings up the allegations of being sexually abused that this is more likely to be the truth than fantasy. This is in contrast to the denial that is thought to persist at some level for many professionals. ${ }^{2}$ Only $5 \%$ of the psychiatrists studied thought that this could be related to the child's fantasies.

\section{Blaming the victim}

No female psychiatrists believed that the sexually abused child provoked the abuse through being attractive and seductive, but $23 \%$ of the male psychiatrists did; $9 \%$ did not know and $68 \%$ agreed with the female psychiatrists.

\section{Offender}

There are many psychiatrists who think that men have a higher sexual drive than women and that it could be related to child sexual abuse; $32 \%$ of the male psychiatrists and $23 \%$ of the female psychiatrists thought so. Of the whole sample, $78 \%$ thought more attention should be paid to the child than the offender, $13 \%$ that they should be both treated equally, and $9 \%$ that more attention should be paid to the offender than the child.

The belief that paedophiliacs responded well to hormone and psychotherapy treatment was held by $17 \%, 14 \%$ did not know, while $68 \%$ thought that the answer was negative.

\section{Information}

It was thought that the abuser was usually somebody a child knew by $97 \%$ and $94 \%$ did not expect to find any physical signs of abuse once the child reported the abuse.

Table I shows some of the recognised consequences of child sexual abuse.

\section{Political stance}

Only $31 \%$ recognised that the issue of power was important in child sexual abuse, $15 \%$ did not know the answer, and $54 \%$ thought that it was unrelated; $86 \%$ did not think that it was domineering father who was more likely to be the offender. 
TABLE I

Some of the recognised consequences of child sexual abuse

\begin{tabular}{lc}
\hline & $\begin{array}{c}\text { \% of psychiatrists } \\
\text { who agreed }\end{array}$ \\
\hline Overdoses & $83 \%$ \\
Prostitution & $74 \%$ \\
Precocious sexual behaviour & $74 \%$ \\
Delinquency & $71 \%$ \\
Poor concentration & $69 \%$ \\
Sexual offences & $66 \%$ \\
Eating disorders & $66 \%$ \\
Murder of the offender & $54 \%$ \\
Murder within the family & $49 \%$ \\
No bad effect whatsoever & $14 \%$ \\
Improvement in child sexual life & $11 \%$ \\
\hline
\end{tabular}

The view that both children and adults coming to see a psychiatrist should be asked for the history of sexual abuse as a matter of routine was expressed by $63 \%, 31 \%$ disagreed, and $6 \%$ were undecided. Interestingly $91 \%$ believed that the abused child would not readily confide in a psychiatrist or a GP.

The psychiatrists were in strong agreement (94\%) that what people do with their children is a matter of public concern, and $89 \%$ thought that psychiatrists should try to influence politicians to change the legislation regarding child sexual abuse if there is need to do so. The firm belief that even if child sexual abuse was common and statistically 'normal' it was a matter for psychiatrists to deal with was held by $94 \% ; 6 \%$ were not sure. Only $23 \%$ related child sexual abuse to the inferior position of women in our society $(46 \%$ of women psychiatrists and $14 \%$ of male psychiatrists). We were not surprised to see that $31 \%$ reported that they had never come across a case of an adult who had been sexually abused as a child. The highest number of cases seen per person was 20 and the average six.

\section{Comment}

Of the sample, $100 \%$ agreed that there was an increase in the number of child sexual abuse cases reported; $89 \%$ said they would believe a child making these allegations; $94 \%$ agreed that it was a matter for the psychiatrist, and that there are psychological consequences. This, however, is in sharp contrast to the number of cases reported, e.g. $31 \%$ have never seen a case and the majority thought that the enquiry into past history of sexual abuse in childhood should be made.
The psychiatrists were fairly well informed and recognised the psychological consequences of child sexual abuse, but were not using this information in their clinical practice. In attempting to explain this we need to look at issues of taboo. The high incidence of incest evidently demonstrates that there is less of a taboo against the act of incest than against the acknowledgement of the act.

This is the first study looking at the attitudes of adult psychiatrists towards incest, which is in itself surprising. Strong feelings were raised by this research and the feelings of the researchers were that there was some reluctance to answer the questionnaire and in particular to look at clinical attitudes. Five female and two male subjects said they were abused themselves as children, although we never attempted to collect this sort of data. These subjects were well aware of the consequences of abuse and had a more positive attitude towards this research.

The sociological view is that issues of power are important in child sexual abuse and it is known that the fear of the perpetrator is important. ${ }^{3}$ Yet only $31 \%$ of the sample recognised that the issue of power was significant. Sexual abuse results de facto from the abuse of power. The results of the questionnaire strongly suggest a denial of this. This could be related to a denial of the power difference between patient and doctor mirroring the original incestual relationship.

Although this was a limited pilot study involving a relatively small number of subjects, it does indicate the need to look at the types of questions asked in a psychiatric history and that the question of incestual relationships in the aetiology of neurotic disorders needs more extensive investigation.

\section{Acknowledgements}

We are most grateful to Dr Dora Black and Dr Morris Fraser for inspiration and their very useful comments. We also thank our colleagues for completing the questionnaire.

\section{References}

${ }^{1}$ BAKER, A. W. \& DunCAN, S. P. (1984) Child sexual abuse a study of prevalence in Great Britain. Channel 4/MORI Poll for Gambles Milne Ltd 1984.

${ }^{2}$ EDITORIAL (1986) Childhood depression and sexual abuse. Lancet, I, 196.

${ }^{3}$ Burgess, A. W. \& Holmstrom, L. L. (1975) Sexual assault of children and adolescents: Pressure, sex and secrecy. Nursing Clinics of North America, September 1975, 55-63. 